\title{
Potentially Alarming Trends in the Scope of Practice for Family Physicians
}

Peter J. Carek, MD, MS

In this issue, Peterson et $\mathrm{al}^{1}$ report on the substantial gaps between preparation for, and practice of, nearly all clinical-practice areas among family physicians. They conclude that early-career family physicians may not find opportunities to provide the broad and comprehensive care consistent with their training. This report is a followup to the Coutinho $^{2}$ study of family physicians registering for the American Board of Family Medicine (ABFM) Certification Examination that found graduating family-medicine residents reported an intention to provide a broader scope of practice than that reported by current practitioners.

The largest differences between reported intentions to practice and actual practice included prenatal care, home visits, nursing home care, inpatient care, and obstetric care. Other specific clinical activities with differences of greater than $5 \%$ between reported intentions to practice and actual practice included acute/same-day care, chronic-disease management, women's health, sports medicine. Although statistically significant differences were noted in all clinical activities, the clinical and service relevance of these differences would require further study. Besides finding opportunities to provide the broad and comprehensive care, the scope of practice by an individual physician is multifactorial and dependent on such influences as geographic factors, availability of health-care resources to the main practice setting, and practice-organiza-

From the Department of Community Health and Family Medicine, College of Medicine, University of Florida, Gainsville, FL.

Funding: none.

Conflict of interest: none declared.

Corresponding author: Peter J. Carek, MD, MS, Department of Community Health and Family Medicine, College of Medicine, University of Florida, P.O. Box 100237, Gainesville, FL 32610-0237 (E-mail: carek@ufl.edu).

\section{See Related Article on Page 181.}

tion's factors as well as physician-related factors such as training and intention to provide specific services. ${ }^{3}$

The current report and the specific results of the study seem to announce a marked decrease in the scope of clinical services and care being provided by family physicians. ${ }^{1,2}$ For some clinical services provided, this assumption is probably true and would impact the comprehensiveness of care being provided by these physicians. For other services, the differences may be clinically insignificant. The provision of prenatal and maternity care by family physicians has decreased for many years and the impact of this change has yet to be fully recognized. ${ }^{4,5}$ Although the number of family physicians providing inpatient care is decreasing, many patients previously admitted with certain conditions are now treated for these same conditions by family physicians on an outpatient basis. Furthermore, inpatient care is becoming increasingly complex and probably requires a team of health-care providers with a new model of care. Nursing-home care is often provided by family physicians with additional training in geriatrics. Although many family physicians may not provide home visits, home health services provided under the direction and orders of a family physician may be growing.

Although not included in their policy brief ${ }^{1}$, perhaps most alarming among the Coutinho study ${ }^{2}$ finding may be the number of both initial certifiers and recertifying physicians who do not provide or who do not plan to provide services and care that are considered to be basic services provided by a family physician. As noted in the results, not all family physicians (both initial certifiers and recertifying physicians) are providing certain basic services: chronic-disease management ( $94.5 \%$ vs $86.9 \%$, respectively), preventive services ( $95.5 \%$ vs $87.2 \%$ ), pediatric care $(91.4 \%$ vs $89.6 \%)$, women's health ( $87.4 \%$ vs $82.2 \%)$, mental health $(80.9 \%$ vs $78.6 \%)$, and musculoskeletal care $(93.2 \%$ vs $90.9 \%)$. Nota- 
bly, these results are from the information obtained from practicing family physicians (ie, physicians who did not provide direct patient care were excluded from the study). Not having all or nearly all family physicians provide these basic services seems to contradict the premise of primary care and affects the value of family medicine in the current health-care system.

In a 1996 study, the National Academy of Medicine (formerly the Institute of Medicine) defined comprehensiveness as "the provision of integrated, accessible health care services by clinicians who are accountable for addressing a large majority of personal health needs." Comprehensiveness means that all problems in the population should be cared for in primary care (with short-term referral as needed), except those that are too unusual (generally a frequency of less than 1 or 2 per thousand in the population served) for the primary-care practitioner or team to treat competently. ${ }^{7}$

As noted by the American Academy of Family Physicians (AAFP), "family physicians deliver a range of acute, chronic, and preventive medical care services." ${ }^{8}$ Furthermore, these physicians "also provide preventive care, including routine checkups, health-risk assessments, immunization and screening tests, and personalized counseling on maintaining a healthy lifestyle." This statement seems to contradict the responses of over 300 initial certifying family physicians and over 1000 currently practicing family physicians who indicate that they do not plan to or are currently providing these services or may be omitting certain populations (women and children).

The underlying principle of comprehensive care provided by a competent family physician who provides high-quality care to individuals and population of patients is fundamental to family-medicine residency education and continues to be an emphasis of residency training requirements. Any concern about comprehensive care provided by family physicians is lessened if we are noting a small but not insignificant number of family physicians not providing the basic services associated with primary care. During the early years of the discipline, the Council on Medical Education of the American Medical Association published the report titled, "The Graduate Education of Physicians," which emphasized that comprehensive care such as delivered by the family physician is a high calling. ${ }^{9}$ As part of an accredited program, residents must be provided the opportunities to gain the necessary knowledge, skills, and experience needed for independent practice as a family physician. ${ }^{10}$ Therefore, the requirements for graduate medical education in family medicine developed by the Residency Review Committee for Family Medicine emphasize education in an environment demonstrating that "continuity of comprehensive care for the diverse patient population family physicians serve is foundational to the specialty." In this setting, a graduate of an accredited family medicine residency program has the attitude, knowledge, skills, and experience to provide high-quality and comprehensive care to individual patients, communities, and populations. This high-quality and comprehensiveness of care should be expected regardless of the community or setting being served. As a core element of comprehensive care, basic services should and need to be provided for the betterment of the patients and health-care system.

Ultimately, the comprehensive services provided by a primary-care practice is associated with better overall health. As summarized by Starfield et $\mathrm{al}^{7}$, the characteristics of primary-care practice present in countries with high primary-care scores and absent in countries with low primary-care scores were the degree of comprehensiveness of primary care (ie, the extent to which primary-care practitioners provided a broader range of services rather than making referrals to specialists for those services). In a more recent study, increasing family physician comprehensiveness of care, especially as measured by using the Medicare Part A and B or the Part B payment measure, is associated with lower average payments per patient. ${ }^{11}$ The comprehensive care described in these studies intuitively would include the basic services of chronic disease management, preventive care, pediatric care, women's health, mental health, and musculoskeletal care.

In conclusion, the policy brief by Peterson ${ }^{1}$ and the study by Coutinho ${ }^{2}$ demonstrate a decrease in the scope of care being provide by many family physicians. Potentially more alarming is the finding that many family physicians are no longer planning to or provide the basic services associated with a primary care physician. Our educational organizations (ie, Accreditation Council for Graduate Medical Education and Society of Teacher of Family Medicine) need to ensure that family physicians receive the training necessary to provide comprehensive care built on a foundation of basic primary 
care services. In addition, the AAFP along with the ABFM must make every effort possible through recognition and board certification to ensure that as many family physicians as possible are providing the basic services of primary care fundamental and essential to the overall care provided by a family physician and fundamental to the health of our patients.

To see this article online, please go to: bttp://jabfm.org/content/ 31/2/178.full.

\section{References}

1. Peterson LE, Fang B, Puffer JC, Bazemore AW. Wide gap between preparation and Scope of practice of early career family physicians. J Am Board Fam Med 2018;31;181-182.

2. Coutinho AJ, Cochrane A, Stelter K, Phillips RL Jr, Peterson LE. Comparison of intended scope of practice for family medicine residents with reported scope of practice among practicing family physicians. JAMA 2015;314:2364-72.

3. Wong E, Stewart M. Predicting the scope of practice of family physicians. Can Fam Physician 2010;56: e219-25.

4. Tong ST, Makaroff LA, Xierali IM, et al. Proportion of family physicians providing maternity care continues to decline. J Am Board Fam Med 2012;25:270-1.

5. Barreto TW, Eden AR, Petterson S, Bazemore AW, Peterson LE. Intention versus reality: Family medi- cine residency graduates' intention to practice obstetrics. J Am Board Fam Med 2017;30:405-6.

6. Donaldson MS, Yordy KD, Lohr KN, Vanselow NA. Primary care: America's health in a new era. Washington, DC: National Academies Press; 1996.

7. Starfield B, Shi L, Macinko J. Contribution of primary care to health systems and health. Milbank Q 2005;83:457-502.

8. American Academy of Family Physicians. Family Medicine Specialty. Available from: https://www.aafp. org/about/the-aafp/family-medicine-specialty.html. Accessed January 14, 2018.

9. Millis JS, Boyer R, Cole WH, et al. The graduate education of physicians: The report of the Citizens Commission on Graduate Medical Education. Chicago, IL: American Medical Association; 1966.

10. American College of Graduate Medical Education. ACGME program requirements for graduate medical education in family medicine. Available from: https://www.acgme.org/acgmeweb/Portals/ 0/PFAssets/ProgramRequirements/120_family_ medicine_07012014.pdf. Updated 2014. Accessed January 9, 2018.

11. Bazemore A, Petterson S, Peterson LE, Phillips RL. More comprehensive care among family physicians is associated with lower costs and fewer hospitalizations. Ann Fam Med 2015;13:206-13. 